\title{
Synthesis and adsorption properties of activated carbon from KOH-activation of Moroccan Jujube shells for the removal of COD and color from wastewater
}

\author{
Mohammed Kachabi ${ }^{1}$, Imane El Mrabet ${ }^{1}$, Zineb Bencheqroun ${ }^{1}$, Mostafa Nawdali ${ }^{2}$ and Hicham Zaitan ${ }^{1, *}$ \\ ${ }^{1}$ Laboratory LCMC, Faculty of Science and Technology, Sidi Mohamed Ben Abdellah University, B.P. 2202, \\ Fez, Morocco \\ ${ }^{2}$ Laboratory LCMC, Polydisciplinary Faculty, Sidi Mohamed Ben Abdellah University, B.P. 1223, Taza,
}

Morocco

\begin{abstract}
This study aimed to investigate the applicability of new low-cost activated carbons with a high surface area prepared by $\mathrm{KOH}$ chemical activation of jujube shells (denoted JSAC) as adsorbent of Chemical Organic Demand (COD) from wastewater.

The prepared activated carbon is characterized by various physical-chemical methods to determine their morphological, textural and chemical characterization, including nitrogen adsorption-desorption isotherms, Fourier transform infrared spectroscopy (FTIR), Scanning electron microscopy (SEM), Boehm titration method and the $\mathrm{pH}$ of the point of zero charge $\left(\mathrm{pH}_{\mathrm{PZC}}\right)$.

Then they were used as an adsorbent for the removal of COD from wastewater collected from Fez area. Adsorption equilibrium and kinetic data were determined and fitted to several adsorption isotherms and kinetics models, respectively. The results showed that the Langmuir isotherm fitted well the equilibrium data of COD on JSAC adsorbent; whereas, the kinetic data were best fitted by the pseudo-second-order model. This adsorbent showed the highest removal efficiency for COD (72\%) and the grey colour of the wastewater $(83 \%)$ for an optimum dose of $0.5 \mathrm{~g}_{\mathrm{JSAC}}$. $\mathrm{L}^{-1}$. Results from the study showed that JSAC activated carbon could be utilized as an effective and less expensive adsorbent for the removal of COD in wastewater.
\end{abstract}

Keywords: Jujube shells JSAC, adsorption, wastewater, COD reduction

\section{Introduction}

Nowadays, the development of human activities and population growth, conventional water resources are becoming increasingly limited, and the volumes of wastewater discharges are continually increasing. Wastewaters containing aromatic organic compounds (refractory, toxic and inhibitory) must be treated before they discharged into waste treatment systems. The discharge of raw wastewater poses a grave danger on the environment and human health if they are not properly collected, treated and safely disposed of.

In order to alleviate the effects of untreated wastewater on the environment and to reach the liquid discharge standards, various techniques, including filtration, coagulation-flocculation, chemical precipitation, membrane separation, adsorption, advanced oxidation process,

*Corresponding author: Hicham Zaitan

Email address: hicham.zaitan@usmba.ac.ma

DOI: http://dx.doi.org/10.13171/mjc8319050704hz bioremediation and electrochemical technologies, have been continuously developed to pursue efficient

COD removal, which is a significant contaminant urban and/or industrial wastewater ${ }^{1-3}$. Among all of them, the adsorption process by activated carbon provides an attractive alternative treatment and is superior in water reuse, mainly due to its performance, simple design and easy use ${ }^{4-6}$. The cost of commercially activated carbon is relatively high $^{7}$, and therefore the development and production of effective and low-cost activated carbon adsorbent of properties comparable to those of commercially available using less expensive and available agricultural waste for the removal of various pollutants such as COD from wastewater is attracting more and more attention from researchers ${ }^{7-9}$.

Among natural biomass, jujube (Ziziphus lotus) derived from agricultural by-products is found as a quite abundant species in several regions of Morocco at a low price and belongs to the family

Received January 18, 2019

Accepted March 28, 2019

Published May 7, 2019 
Rhamnaceae. Its fruits used in various fields (aid digestion, claimed to purify the blood) 10,11 has proven to be a promising type of precursor for the synthesis of activated carbon adsorbent to clean polluted water.

The objective of the present work is: (a) to prepare powder activated carbons from Moroccan Jujube shell (JSAC) by $\mathrm{KOH}$-activation and (b) to investigate the applicability of this activated carbon as a low-cost adsorbent for the reduction of COD from the wastewater. The JSAC prepared activated carbons were characterized to determine their pore texture, surface chemistry, and adsorption performance in term of the removal of chemical oxygen demand (COD) and color.

\section{Materials and Methods}

\section{Materials}

\section{Location of the sampling point}

Wastewater samples were taken upstream of the wastewater treatment plant (WWTP) from Fez city (Morocco), located about $10 \mathrm{~km}$ from the center of Fez city in the rural commune of Ain Bouali (province of Moulay Yaâcoub) (see Fig.1). The collected wastewater samples were stored into $25 \mathrm{~L}$ opaque containers, at $4^{\circ} \mathrm{C}$ to minimize the decomposition of organic matter due to microbial activity.

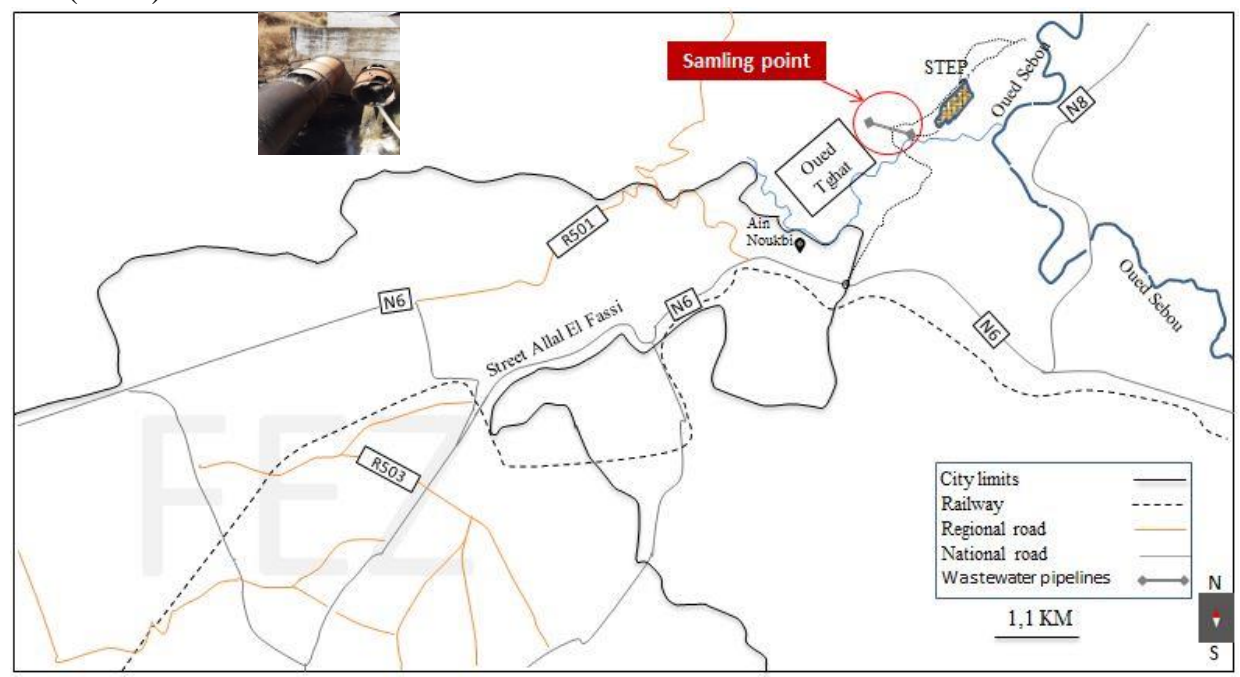

Figure 1. Location of the sampling point

\section{Preparation of JSAC}

Activated carbon was obtained from jujube shells by chemical activation with $\mathrm{KOH}$ following a method previously used by M. Castilla ${ }^{12}$. The raw material was firstly ground and sieved to a particle size between 2 and $3 \mathrm{~mm}$. Portions of jujube shells were mixed with $\mathrm{KOH}$ and water to obtain the slurry with a $\mathrm{KOH} / \mathrm{sample}$ weight ratio of 2 . The slurries were dried at $105^{\circ} \mathrm{C}$ for $48 \mathrm{~h}$. Then, the mixture was activated in a stainless tube in a horizontal cylindrical furnace under $\mathrm{N}_{2}$ flow $\left(300 \mathrm{~mL} \cdot \mathrm{min}^{-1}\right)$ at $300{ }^{\circ} \mathrm{C}$ for $2 \mathrm{~h}$ and then at $840{ }^{\circ} \mathrm{C}$ for $3 \mathrm{~h}$ at a heating rate of $5{ }^{\circ} \mathrm{C} . \mathrm{min}^{-1}$. Then, the tube was cooled to room temperature and the material obtained was washed with $0.1 \mathrm{M} \mathrm{HCl}$ following with distilled water until the $\mathrm{pH}$ value was close to neutral. Subsequently, the activated sample was dried at 105 ${ }^{\circ} \mathrm{C}$ for $12 \mathrm{~h}$ and crushed to $60 \mu \mathrm{m}$, stored for further experimental use.

\section{Characterization of JSAC}

The specific surface area and pore volume of JSAC were determined by nitrogen adsorptiondesorption isotherms at $77 \mathrm{~K}$ with a Micromeritics ASAP 2010 sorptometer. The BET surface area $\left(\mathrm{S}_{\mathrm{BET}}\right)$ was calculated using the Brunauer-Emmett-
Teller (BET) equation in a relative pressure range of $\mathrm{P} / \mathrm{P}_{0}=0.050-0.125$.

In order to remove all physically adsorbed water molecules and other impurities, the JSAC sample was pretreated before analysis at $383 \mathrm{~K}$ for $4 \mathrm{~h}$ under vacuum at $<10^{-2} \mathrm{~Pa}$. The surface morphology of JSAC was analysed using scanning electron microscopy (SEM) on a LEO 435 VP by Field Effect Gun SEM (FEG SEM) using a JEOL 6700S with EDS detector (INCA system, Oxford Instrument). The determination of the concentration of the acid and basic functional groups in the JSAC adsorbent was carried out by the Boehm titration method ${ }^{13}$. Its principle is to place a mass of $0.1 \mathrm{~g} \mathrm{JSAC}$ sample in opaque flasks each containing a solution of $\mathrm{NaOH}$ $(0.1 \mathrm{M}), \mathrm{NaHCO}_{3}(0.05 \mathrm{M}), \mathrm{Na}_{2} \mathrm{CO}_{3}(0.05 \mathrm{M})$, and $\mathrm{HCl}(0.1 \mathrm{M})$. The vials are sealed and shaken at 200 $\mathrm{rpm}$ for $24 \mathrm{~h}$ at room temperature. Then, the supernatant is filtered, and the excess of base or acid was titrated with $\mathrm{HCl}(0.1 \mathrm{M})$ or $\mathrm{NaOH}(0.1 \mathrm{M})$ respectively. According to Boehm method, the number of acid and basic sites were determined under the assumption that $\mathrm{NaOH}$ neutralizes acid sites of different concentrations (carboxylic, lactonic, and phenolic groups) and that $\mathrm{HCl}$ neutralizes basic sites on the surface of the JSAC. 
The $\mathrm{pH}$ of the zero charge point $\left(\mathrm{pH}_{\mathrm{PZC}}\right)$ was determined according to the method reported by Stumm and Morgan ${ }^{14}$. A mass of JSAC sample was placed in contact with a series of opaque vials each containing $20 \mathrm{~mL}$ of $\mathrm{NaCl}$ solution $(0.1 \mathrm{M})$, and their $\mathrm{pH}$ were adjusted to an initial $\mathrm{pH}$ ranging from 2 to 12 using $\mathrm{HCl}$ or $\mathrm{NaOH}$ solution. Nitrogen was bubbled through the solutions. The mixture is stirred for $72 \mathrm{~h}$ at room temperature, and the equilibrium $\mathrm{pH}$ of the solutions was then measured using a $\mathrm{pH}$ meter. The $\mathrm{pH}_{\mathrm{PZC}}$ is determined graphically where $\mathrm{pH}_{\text {final }}=\mathrm{pH}_{\text {initial }}$.

\section{Experimental procedure}

Adsorption isotherm and kinetic
experiments

Adsorption experiments were conducted using a batch method. For which, a series of opaque vials containing $10 \mathrm{mg}$ of the JSAC adsorbent material was added into $20 \mathrm{~mL}$ of wastewater solution. The mixtures were agitated at $200 \mathrm{rpm}$ until the equilibrium was reached. At the end of each experiment, the separation of the two phases liquid and solid was carried out by the centrifugation at $5000 \mathrm{rpm}$ for 10 minutes, and the supernatant was analyzed in terms of chemical oxygen demand (COD), $\mathrm{UV}_{254}$, and color.

The influence of operating conditions (contact time, JSAC dose, solution $\mathrm{pH}$ and temperature) on the adsorption of organic matter expressed as COD onto JSAC was evaluated. The initial COD concentration of wastewater was varied between 10 and $390 \mathrm{mg} \mathrm{O}_{2} \cdot \mathrm{L}^{-1}$. The adsorbent dose of JSAC, $\mathrm{pH}$ of the wastewater, contact time and temperature were adjusted in the range of 0.5 to 2 g. $\mathrm{L}^{-1}, 2-12,0-1500$ $\mathrm{min}$, and $25-35^{\circ} \mathrm{C}$, respectively. Optimum values of the previous parameters were obtained by the highest percentage if removed COD and color.

The total quantity of organic matter at the equilibrium $\left(\mathrm{q}_{\mathrm{e}}, \mathrm{mg} \cdot \mathrm{g}^{-1}\right)$ and any time $\left(\mathrm{q}_{\mathrm{t}}, \mathrm{mg} \cdot \mathrm{g}^{-1}\right)$ expressed as mg COD per gram of JSAC $\left(q_{t, e}, m g . g\right.$ ${ }^{1}$ ) were determined from a mass balance as follows:

$$
q_{t, e}=\frac{\left(C_{0}-C_{t, e}\right) \cdot V}{m}
$$

Where $\mathrm{C}_{0} \quad\left(\mathrm{mg} . \mathrm{L}^{-1}\right) \quad$ and $\quad \mathrm{C}_{\mathrm{t}, \mathrm{e}} \quad\left(\mathrm{mg} . \mathrm{L}^{-1}\right)$ are concentrations of organic matter in the initial state and equilibrium respectively or at a time $\mathrm{t} . \mathrm{m}$ is the mass of the JSAC adsorbent $(\mathrm{g})$, and V is the total volume of the solution (L).

\section{Analytical determinations}

The physicochemical characterization of the wastewater was carried out by standard water and wastewater analysis methods ${ }^{15}$. Wastewater samples were analyzed before and after adsorption treatment.

Analyses of $\mathrm{pH}$, conductivity (CE), turbidity, chemical oxygen demand (COD), biological oxygen demand $\left(\mathrm{BOD}_{5}\right)$ chlorides, nitrates, nitrites, UV- visible absorbance at wavelength $254 \mathrm{~nm}\left(\mathrm{UV}_{254}\right)$ were carried out before treatment The UV-visible absorption measurements were obtained using a UV2300 II spectrophotometer equipped with quartz cuvettes with $1 \mathrm{~cm}$ optical path. The color index (CI) was obtained using the method described by Tizaoui et al. ${ }^{16}$. Before performing spectrophotometric measurements, the samples were filtered or decanted for at least 2 hours to avoid interference due to the presence of suspended matter. The color index is calculated from the absorption coefficients obtained at three different wavelengths in the visible spectrum range, $436 \mathrm{~nm}, 525 \mathrm{~nm}$ and $620 \mathrm{~nm}$, as indicated in equation (2):

$$
C I=\frac{S A C_{436}^{2}+S A C_{525}^{2}+S A C_{620}^{2}}{C A S_{436}+C A S_{525}+C A S_{620}}
$$

With $C A S_{i}=\frac{A b s_{i}}{x}$

Where $\mathrm{Abs}_{\mathrm{i}}$ represents the absorbance of the sample at wavelength $\mathrm{i}$ and $\mathrm{x}$ is the optical path of the cuvette.

COD (mg $\left.\mathrm{O}_{2} \cdot \mathrm{L}^{-1}\right)$ was determined from the closed reflux tube method (5220D) ${ }^{17}$, using a UV2300II spectrophotometer at a maximum wavelength of 600 nm.

\section{Results and Discussion}

\section{Wastewater characterization}

The physicochemical characterization of the raw wastewater from the Fez city are listed in Table 1. Results presented in Table 1 showed that the wastewater of fez city is characterized by very high value in term of $\mathrm{BOD}_{5}\left(405 \mathrm{mg} \mathrm{O} \mathrm{O}_{2} \cdot \mathrm{L}^{-1}\right)$ and suspended matter $\left(1310 \mathrm{mg} . \mathrm{L}^{-1}\right)$ in comparison with the Moroccan standards for liquid discharges. The $\mathrm{COD} / \mathrm{BOD}_{5}$ ratio provides information on the biodegradability of the liquid effluent. Aromatic compounds have a remarkable content in the organic fraction of wastewater determined by measuring the absorbance at $254 \mathrm{~nm}$ (absorption at this wavelength is generally due to the presence of aromatic compounds, phenolic and fulvic compounds).

Another relevant point is some values of physicochemical parameters such as COD, and $\mathrm{BOD}_{5}$ are lower than those found in the industrial wastewater studied by some researchers (Elçin Güneş et al. ${ }^{17}$ and in the so-called complex wastewater studied by Chaouki et al. ${ }^{18}$, Al-Wabel and al $^{19}$ ). However, on the contrary, they are higher than the values found by W. Yang ${ }^{20}$. This difference in composition is mainly due to the different sources of wastewater discharge (industrial and/or domestic). The low COD and $\mathrm{BOD}_{5}$ values in studied effluent can be explained by the dilution caused by domestic wastewater. The $\mathrm{COD} / \mathrm{BOD}_{5}$ ratio of 0.96 explains well the ease of biodegradation of studied liquid 
effluent. The extremely high value of the suspended

matter justifies the turbid staining of the sample.

Table 1. Characterization of wastewater from Fez region

\begin{tabular}{|c|c|c|}
\hline Parameters & Characteristic value & MRR \\
\hline Color & Grey & -- \\
\hline $\mathrm{T}\left({ }^{\circ} \mathrm{C}\right)$ & 22 & 30 \\
\hline $\mathrm{pH}$ & 7.5 & $5.5-9.5$ \\
\hline Turbidity (NTU) & 563 & -- \\
\hline Conductivity $\left(\mu \mathrm{S} . \mathrm{cm}^{-1}\right)$ & 1631 & 2700 \\
\hline Chlorides $\left(\mathrm{mg} . \mathrm{L}^{-1}\right)$ & 1420 & -- \\
\hline Nitrates (mg.L $\left.{ }^{-1}\right)$ & 0.16 & -- \\
\hline Nitrites $\left(\mathrm{mg} . \mathrm{L}^{-1}\right)$ & 0.68 & -- \\
\hline Sulphates (mg.L $\left.{ }^{-1}\right)$ & 151 & 600 \\
\hline $\mathrm{COD}\left(\mathrm{mg}\right.$ of $\left.\mathrm{O}_{2} \cdot \mathrm{L}^{-1}\right)$ & 390 & 500 \\
\hline $\mathrm{BOD}_{5}\left(\mathrm{mg} \cdot \mathrm{L}^{-1}\right)$ & 405 & 100 \\
\hline $\mathrm{COD} \mathrm{BOD}_{5}$ & 0.96 & -- \\
\hline Suspended Matter SM (mg.L $\left.{ }^{-1}\right)$ & 1310 & 100 \\
\hline Color Index & 0.352 & -- \\
\hline
\end{tabular}

* Morocco Reject Requirements (MRR)

\section{Characterisation of JSAC}

The adsorption-desorption isotherms of nitrogen this study at $77 \mathrm{~K}$ illustrated in Figure 2. characterize the JSAC material subject to

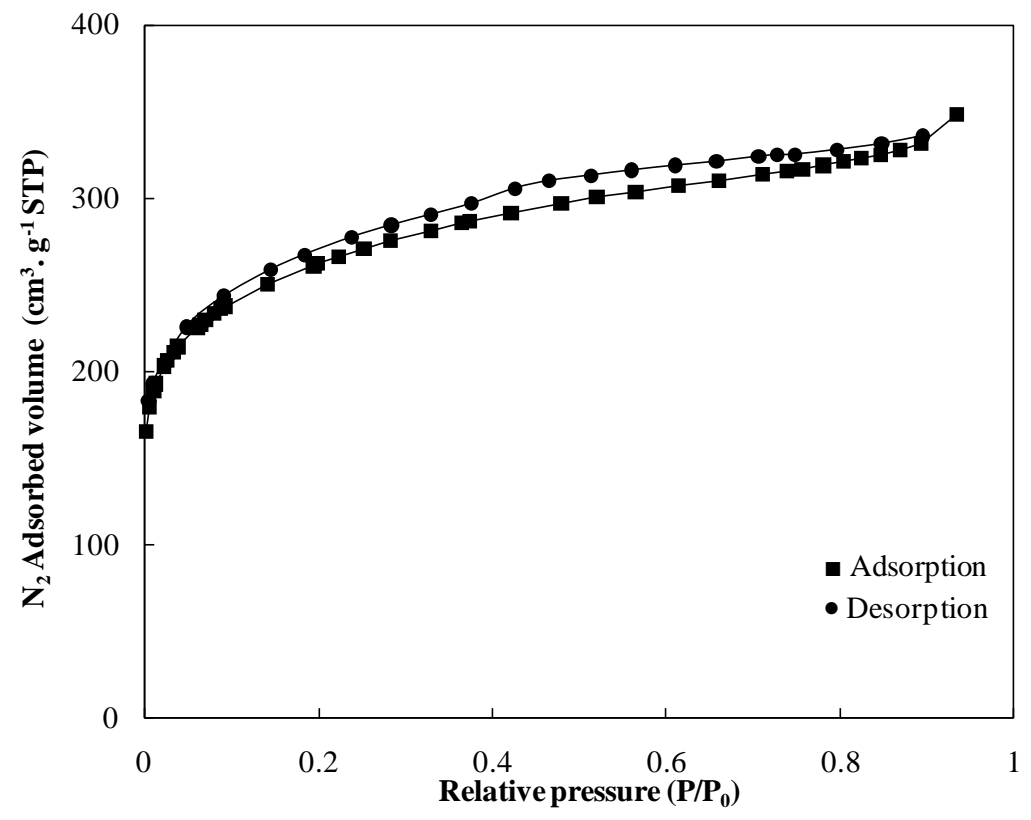

Figure 2. $\mathrm{N}_{2}$ adsorption-desorption isotherms of the JSAC.

The physical adsorption of $\mathrm{N}_{2}$ on JSAC follows a type I isotherm with the existence of a horizontal isotherm characterizing an adsorbent saturation, and a low porosity or microporosity according to the IUJSAC classification. The micropores are filled at pressures that are lower the narrower their width ${ }^{21,22}$. As previously indicated, this material has a very high surface are expressed in $\mathrm{S}_{\mathrm{BET}}$ of $1067 \mathrm{~m}^{2} . \mathrm{g}^{-1}$, with an average pore diameter value of around $1.28 \mathrm{~nm}$ and porous volume of $0.34 \mathrm{~cm}^{3} \cdot \mathrm{g}^{-1}$.
Fig. 3 shows the SEM images of JSAC. According to Fig. 3a and b, it can be observed that JSAC is essentially microporous structure and development of a peculiar porous surface with the average diameter is about $1 \mathrm{~nm}$.

The energy-dispersive X-Ray Spectroscopy (EDX spectrum) (Fig. 3c) obtained, shows that JSAC is mainly composed of $\mathrm{O}(72.3 \%), \mathrm{C}(26.9 \%)$ and a small amount of $\mathrm{P}, \mathrm{Mg}, \mathrm{Ca}$ and $\mathrm{K}$. 


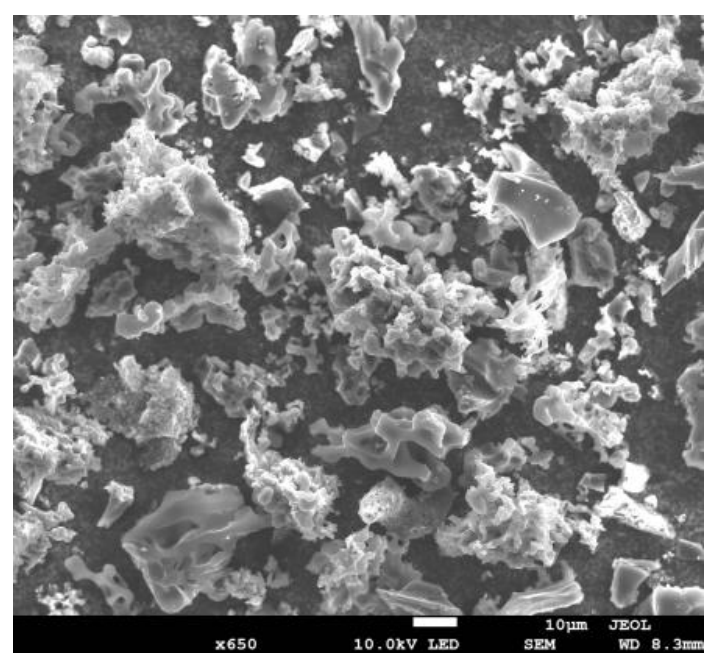

(a)

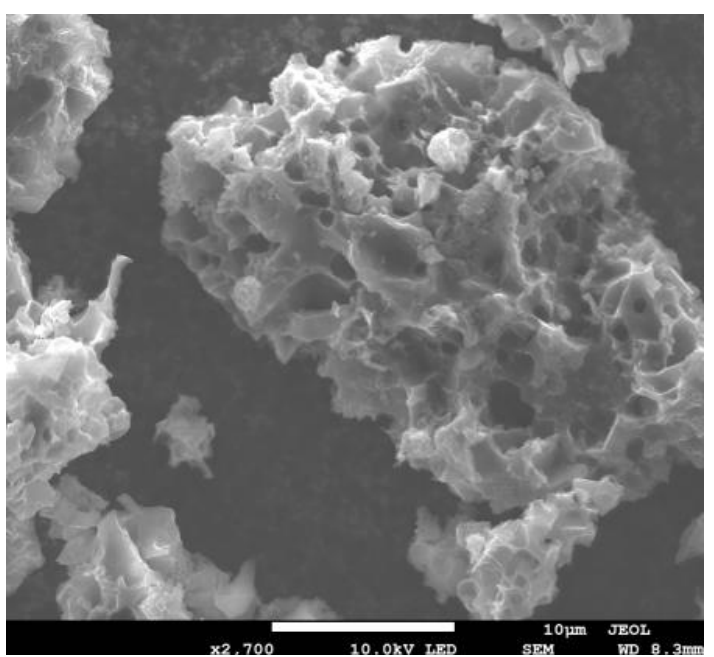

(b)

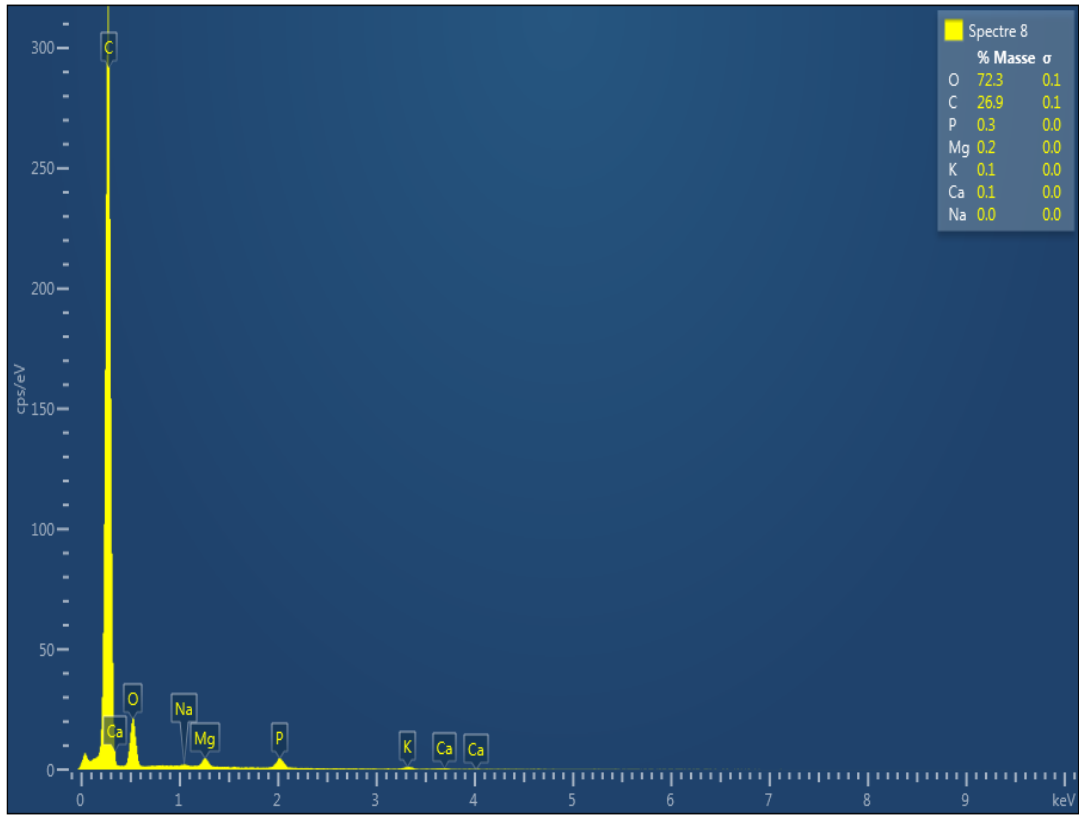

(c)

Figure 3. SEM micrographs of JSAC adsorbent with different resolutions (a) 650x, (b) 2700x and EDX spectrum.

Results of the quantitative analysis of the functional groups of the JSCA surface using the Boehm method are presented in Table 2. The functional groups existing on the surface of the adsorbent have very important effects on the adsorption process since they act as active sites capable of interacting with organic molecules ${ }^{23}$. The $\mathrm{pH}$ value at the zero-charge point $\left(\mathrm{pH}_{\mathrm{PZC}}\right)$ is determined when the correlation between the initial $\mathrm{pH}$ and $\Delta \mathrm{pH}$ is zero ${ }^{24}$. The basic character of the JSAC is in agreement with the $\mathrm{pH}_{\mathrm{PZC}}$ value previously measured which is equal to 9 . JSAC has the greatest content of basic groups $\left(0.031 \mathrm{mmol} . \mathrm{g}^{-1}\right)$. The presence of basic groups enhances the adsorption of organic compounds through the formation of an electron acceptor-donor complex. Concerning the acidic functional groups, the phenolic groups are the most important for the JSAC.

Thus, the material behaves as a substrate of positive surface charge when the $\mathrm{pH}$ of the solution is below $\mathrm{pH}_{\mathrm{PZC}}$ and vice versa. The deprotonation of oxygen-containing acid groups can explain the negative charge of JSAC at $\mathrm{pH}$ above $\mathrm{pHPZC}$.

Table 2. Content of surface functional groups in JSAC determined by Boehm method

\begin{tabular}{|c|c|c|c|c|c|c|}
\hline Sample & $\begin{array}{c}\text { Carboxylic } \\
\text { group } \\
\left(\mathrm{mmol}_{\mathrm{g}} \mathrm{g}^{-1}\right)\end{array}$ & $\begin{array}{c}\text { Phenolic } \\
\text { group } \\
\left(\mathrm{mmol}^{-1}\right)\end{array}$ & $\begin{array}{c}\text { Lactonic } \\
\text { group } \\
\left(\mathrm{mmol}^{-1}\right)\end{array}$ & $\begin{array}{c}\text { Total basic } \\
\text { sites } \\
\left(\mathrm{mmol}^{-1}\right)\end{array}$ & $\begin{array}{c}\text { Total Acidic } \\
\text { sites } \\
\left(\mathrm{mmol}^{-1}\right)\end{array}$ & $\begin{array}{c}\text { Total } \\
\left(\mathrm{mmol} . \mathrm{g}^{-1}\right)\end{array}$ \\
\hline JSAC & 0.001 & 0.0045 & 0.002 & 0.031 & 0.007 & 0.038 \\
\hline
\end{tabular}




\section{Removal of COD in wastewater by adsorption}

Effect of adsorbent dosage, $\mathbf{p H}$ and contact time on the removal of $\mathrm{COD}, \mathrm{UV}_{254}$ and color

The dose of the adsorbent is an essential factor that directly influences the cost of the adsorption process. Thus, in this study, the removal of the initial COD (390 mg O $2 . \mathrm{L}^{-1}$ ) and turbidity (563 NTU) is performed by an adsorption process using a quantity of JSAC between 0-2 g.L ${ }^{-1}$.

Fig. 4 shows the evolution of COD and $\mathrm{UV}_{254}$ reduction as a function of JSAC doses at $25^{\circ} \mathrm{C}$. To further investigate the characteristics of organic matter, the absorbance values at $254 \mathrm{~nm}\left(\mathrm{UV}_{254 \mathrm{~nm}}\right)$ are used here as an indicator of aromatic or conjugated double-bond compounds. It can be seen that an increase in the adsorbent dose from $0.25 \mathrm{~g} . \mathrm{L}^{-1}$ to $0.5 \mathrm{~g} . \mathrm{L}^{-1}$ leads to an increase in the removal efficiency of COD and decrease of $\mathrm{UV}_{254}$ indicating that the adsorption process could partially remove aromatic compounds. Such results can be attributed to the higher availability of actives sites and the specific surface area. However, above 0.5 g. $\mathrm{L}^{-1}$ a further increase in the JSAC dose does not affect the removal of $\mathrm{COD}$ and $\mathrm{UV}_{254}$, which reflects the saturation of the adsorption sites. Also, the unavailability of adsorption sites where the JSAC dose exceeds 1 g. $\mathrm{L}^{-1}$ can be interpreted by the particle-particle interactions of the adsorbent forming aggregates which reduce the probability that organic molecules of the solution are adsorbed at the contact sites of the two particles ${ }^{25}$. Results indicate that the optimal JSAC adsorbent dosage for removal of COD is 0.5 g.L $\mathrm{L}^{-1}$.

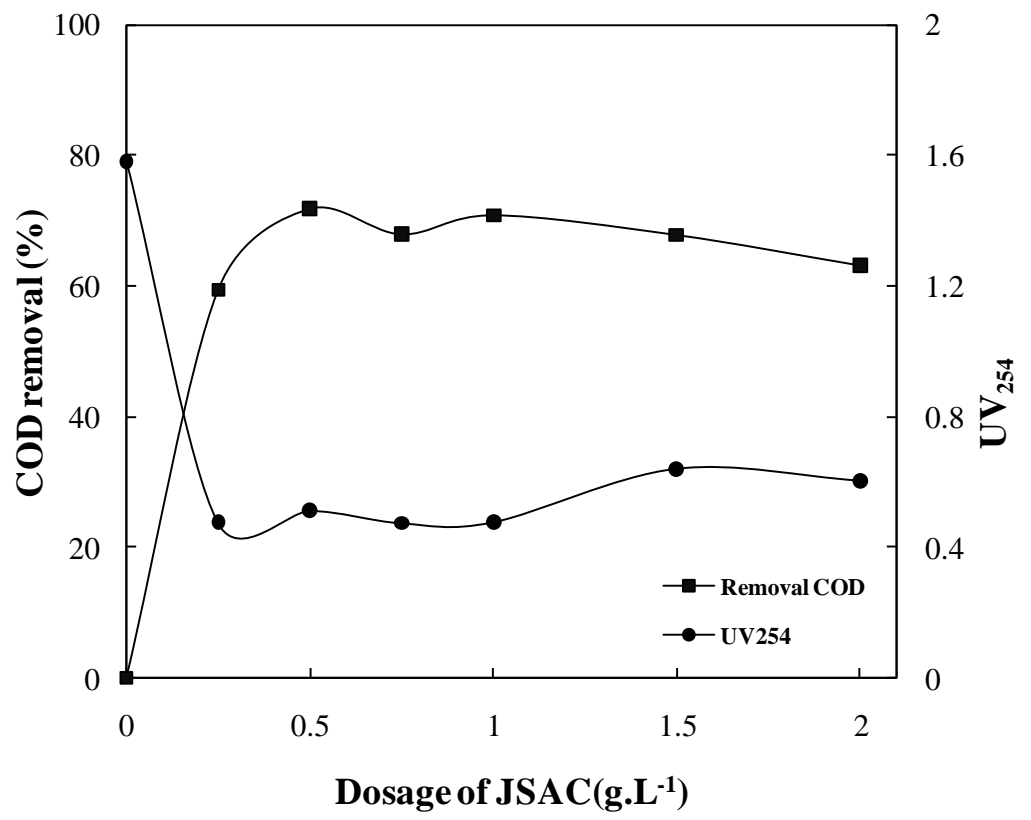

Figure 4. Removal of COD and $\mathrm{UV}_{254}$ for different dosages of JSAC

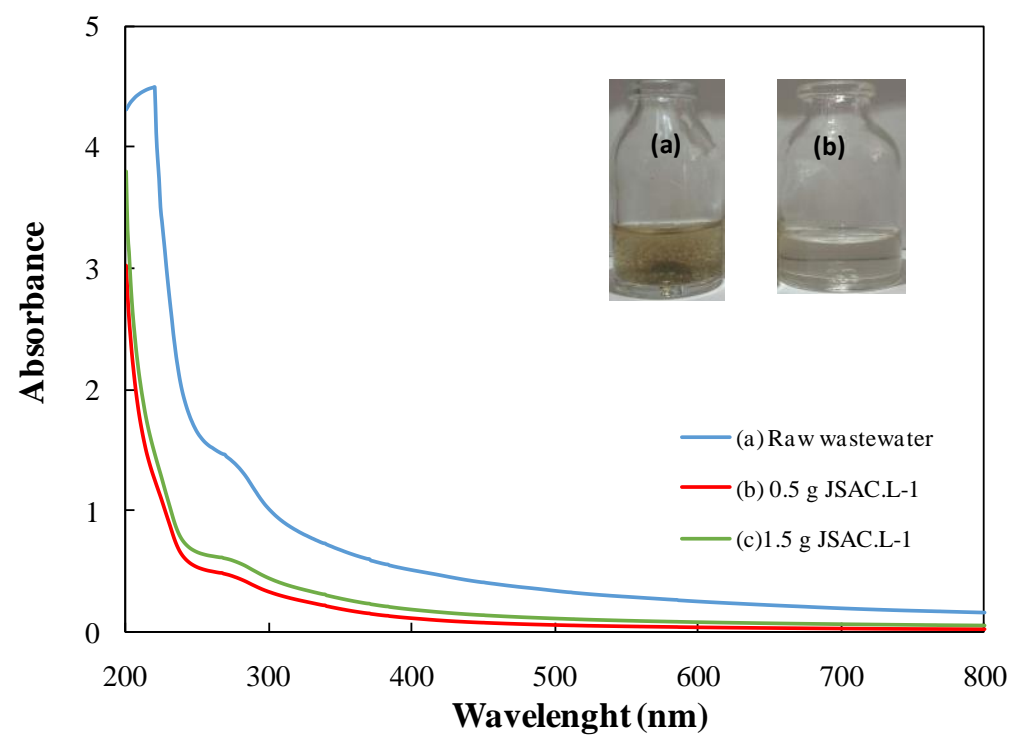

Figure 5. UV-vis absorbance spectra of the wastewater before and after adsorption onto JSAC. 
The UV-vis spectra of wastewater before and after adsorption treatment process on different doses of JSAC are shown in Figure 5. For raw wastewater, strong adsorption takes place indicating the presence of a large amount of aromatic compounds. It is clear from the spectra that the absorbance of the UV-vis at the wavelengths range $(200-800 \mathrm{~nm})$ decreases significantly after treatment by the adsorption process, thus changing the characteristic turbid color of the raw wastewater, which becomes clear after sludge separation. It should be noted that a significant reduction in color is achieved by this process, which is worth $83 \%$. This value is calculated by measuring the absorbance at three wavelengths in the visible range, namely $436 \mathrm{~nm}$, $525 \mathrm{~nm}$ and $620 \mathrm{~nm}$ (see Eqs 2 and 3).

As can be seen, the adsorption treatment showed efficiency in the removal of COD, $\mathrm{UV}_{254}$ and color with percentages of $72 \%, 67.61 \%$ and $83 \%$ respectively. Consequently, the treated wastewater meets the quality standards required by Morocco.
These results indicate that adsorption on JSAC could be used as a primary, secondary or tertiary process for wastewater treatment in the city of Fez.

It has been found that the $\mathrm{pH}$ of wastewater is the most important factor in determining adsorbateadsorbent interactions. The effect of initial solution $\mathrm{pH}$ on the COD removal in wastewater with JSAC was also studied by varying the $\mathrm{pH}$ from 2 to 12 at a constant JSAC dose $\left(0.5 \mathrm{~g} . \mathrm{L}^{-1}\right)$, constant initial concentration of COD $\left(390 \mathrm{mg} \quad \mathrm{O}_{2} \cdot \mathrm{L}^{-1}\right)$ and temperature $\left(25^{\circ} \mathrm{C}\right)$. The typical $\mathrm{pH}$ of the urban wastewater was about 7.5 and it was adjusted to the desired value by addition of dilute $\mathrm{HCl}$ or $\mathrm{NaOH}$ solutions.

The results of the equilibrium uptake as a function of $\mathrm{pH}$ for JSAC adsorbent are illustrated in Fig. 6. As can be seen, JSAC showed a maximum removal percentage of COD $(73.5 \%)$ with $\mathrm{pH}$ change between 6 and 10 (neutral $\mathrm{pH}$ domain).

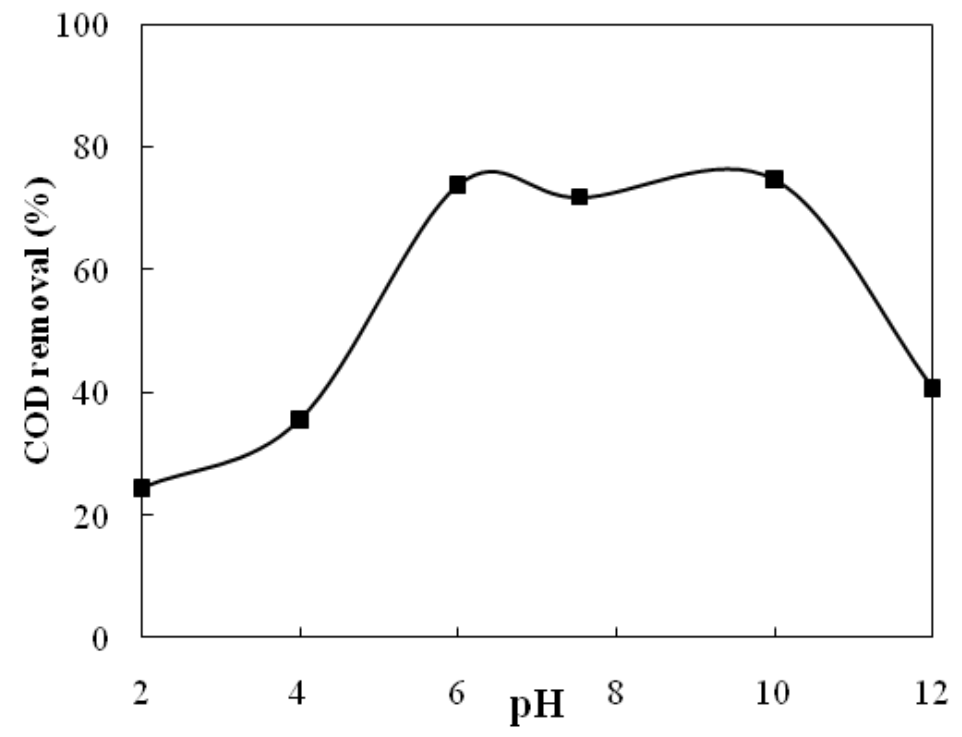

Figure 6. Effect of solution $\mathrm{pH}$ on COD removal by adsorption onto JSAC at $25^{\circ} \mathrm{C}$.

According to Cossu and Rossetti's ${ }^{26}$ studies on complex wastewater, the fraction of organic matter most likely to be removed by activated carbon adsorption is due to fulvic acids with a molecular weight (100 to 10000 g.mol $\left.{ }^{-1}\right)$.

The $\mathrm{pH}$ effect on adsorption gave rise to three zones: (a) an increase in $\mathrm{pH}$ value from 2 to 6 shows an improvement in COD removal from $24.5 \%$ to 73 . $5 \%$, (b) then a stabilization of COD removal at $73.5 \%$ in the $\mathrm{pH}$ range between 6 and 10 and (c) finally a progressive decrease in removal efficiency at $\mathrm{pH}$ values above 10 .

The gradual increase in COD removal percentages as a function of solution $\mathrm{pH}(2-6)$ can be attributed to the presence of $\mathrm{H}_{3} \mathrm{O}^{+}$ions. This, in turn, neutralized the negatively charged adsorbent surface, thereby reducing hindrance to the diffusion of organic molecules. At high $\mathrm{pH}$, the reduction in adsorption capacity of JSAC may be possible due to the abundance of $\mathrm{OH}^{-}$ions which obstruct the diffusion of organic (contributing to COD) ions ${ }^{27}$. Such interactions can mutually inhibit the adsorption of organic matter on the JSAC. Das et al has also reported similar observations.

In order to investigate the minimum contact time for high amount adsorption of COD, adsorption experiments of COD from wastewater were performed at different time intervals, keeping constant volume $(\mathrm{V}=500 \mathrm{~mL})$, the initial concentration of COD $\left(390 \mathrm{mg} \mathrm{O} \mathrm{O}_{2} \cdot \mathrm{L}^{-1}\right)$ at room temperature and applying a dose of JSAC of 0.5 g.L $\mathrm{L}^{-1}$. Fig. 7 shows the evolution of the amount of COD adsorbed onto JSAC as a function of contact time. 


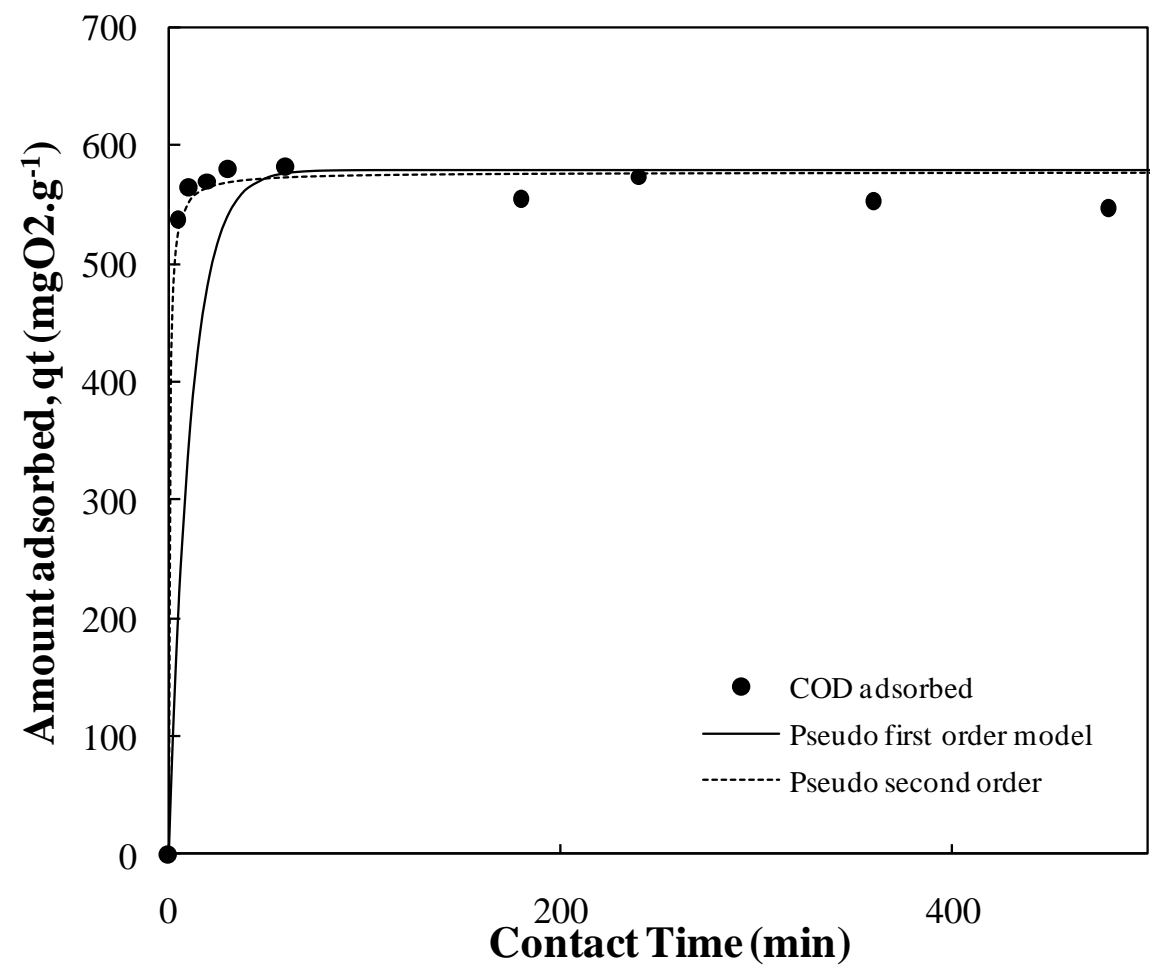

Figure 7. Kinetics of the adsorption of COD onto JSAC

Results obtained showed that the adsorption equilibrium could be practically achieved $30 \mathrm{~min}$. Under these conditions, the COD removal efficiency is approximately $74.5 \%$ corresponding to $550 \mathrm{mg} . \mathrm{g}^{-1}$ of COD. The very sharp increase in the initial stage of the adsorption process as shown in Figure 7 explains the availability of accessible sites $^{28}$ and confirmed strong interactions between the COD and the adsorbent. As the treatment time progressed, the adsorbent sites had the tendency towards saturation and the process becomes slower. This phenomenon can be related to a reduction in the quantity instantly adsorbed by JSAC adsorbent due to the absence of easily accessible sites for the organic matter uptake, which in turn leads to film diffusion ${ }^{29}$.

In order to understand the behavior of the JSAC adsorbent towards COD and to better control the mechanism during the adsorption process, two models were adopted to process the experimental data. A first-order and second-order pseudo were analyzed as a function of the regression coefficient $\left(\mathrm{R}^{2}\right)$, and the amount of COD adsorbed at equilibrium $\left(\mathrm{q}_{\mathrm{e}}\right)$.

The kinetic model of the first order pseudo ${ }^{30}$ is given by:

$$
q_{t}=q_{e}\left(1-e^{-k_{1} t}\right)
$$

With $\mathrm{q}_{\mathrm{t}}$ and $\mathrm{q}_{\mathrm{e}}\left(\mathrm{mg} \cdot \mathrm{g}^{-1}\right.$ ) are respectively the adsorption capacities at time $t$ and equilibrium, $\mathrm{k}_{1}\left(\mathrm{~h}^{-}\right.$ ${ }^{1}$ ) is the velocity constant of the first order pseudo model. This constant is obtained by plotting $q_{t}$ as a function of time.

The kinetic model of the pseudo-second order reported by Ho and McKay ${ }^{31}$ is given by:

$q_{t}=\frac{k_{2} q_{e}^{2} t}{1+k_{2} q_{e} t}$

With $\mathrm{k}_{2}\left(\mathrm{~g} \cdot \mathrm{mg}^{-1} \cdot \mathrm{h}^{-1}\right)$ is the adsorption constant.

The parameters presented in Table 3 characterizing the kinetic models were calculated using the Origin software. From Table 3, it can be seen that the values of the coefficient of determination $\left(\mathrm{R}^{2}\right)$ of the models studied to confirm that the pseudo-second-order model describes the experimental data $\left(\mathrm{R}^{2} \sim 0.98\right)$ very well with a calculated value of the adsorption capacity variable $\left(q_{e}\right)$ very close to the experimental capacity.

The pseudo-second-order model suggests that the interactions of organic matter with JSAC are properly chemical. 
Table 3. Kinetic parameters for the adsorption of COD onto JSAC.

Kinetic model

\begin{tabular}{|l|l|}
\hline Parameters & Values \\
\hline $\mathrm{q}_{\text {exp }}\left(\mathrm{mg} \cdot \mathrm{g}^{-1}\right)$ & 580 \\
\hline $\mathrm{q}_{\mathrm{e}}\left(\mathrm{mg} \cdot \mathrm{g}^{-1}\right)$ & 578.0 \\
\hline $\mathrm{k}_{1}$ & 0.004 \\
\hline $\mathrm{R}^{2}$ & 0.97 \\
\hline $\mathrm{q}_{\mathrm{e}}\left(\mathrm{mg} \cdot \mathrm{g}^{-1}\right)$ & 578.0 \\
\hline $\mathrm{k}_{2}$ & 0.09 \\
\hline $\mathrm{R}^{2}$ & 0.98 \\
\hline
\end{tabular}

\section{Adsorption isotherms}

The adsorption isotherm indicates how the adsorbate molecules are distributed between the liquid and solid phases when the adsorption process reaches the equilibrium and used for the optimization, design and sizing of the adsorption process. Fig. 8 represents the amount adsorbed COD onto JSAC at the equilibrium $\left(\mathrm{q}_{\mathrm{e}}\right)$ as a function of the COD concentration $\theta$ fat equilibrium. It is important to note that the experimental data on COD adsorption at three different temperatures of $25^{\circ} \mathrm{C}$, $30^{\circ} \mathrm{C}$ and $35^{\circ} \mathrm{C}$ can be linked to the models described by the Langmuir ${ }^{32}$ adsorption isotherms (see Fig. 8). Values for the determined parameters of the model studied are listed in Table 4.
In this work, adsorption isotherms express the adsorption of COD quantities by mass of JSAC, $\mathrm{q}_{\mathrm{e}}$ (mg. $\mathrm{g}^{-1}$ ), as a function of the equilibrium COD concentration, $\mathrm{C}_{\mathrm{e}}\left(\mathrm{mg} \mathrm{O}_{2} \cdot \mathrm{L}^{-1}\right)$, as follows:

Equation of Langmuir:

$$
q_{\mathrm{e}}=\frac{q_{\mathrm{m}} K_{\mathrm{L}} C_{\mathrm{e}}}{1+K_{\mathrm{L}} C_{\mathrm{e}}}
$$

With $\mathrm{q}_{\mathrm{m}}\left(\mathrm{mg} \mathrm{O} \mathrm{O}_{2} \cdot \mathrm{g}^{-1}\right)$ is the maximum capacity that an adsorbent can adsorb and which depends on the adsorption capacity of the monolayer and $\mathrm{K}_{\mathrm{L}}$ $\left(\mathrm{L}_{\mathrm{mg}} \mathrm{m}^{-1}\right)$ is the Langmuir adsorption equilibrium constant which depends on the affinity of the adsorbent sites.

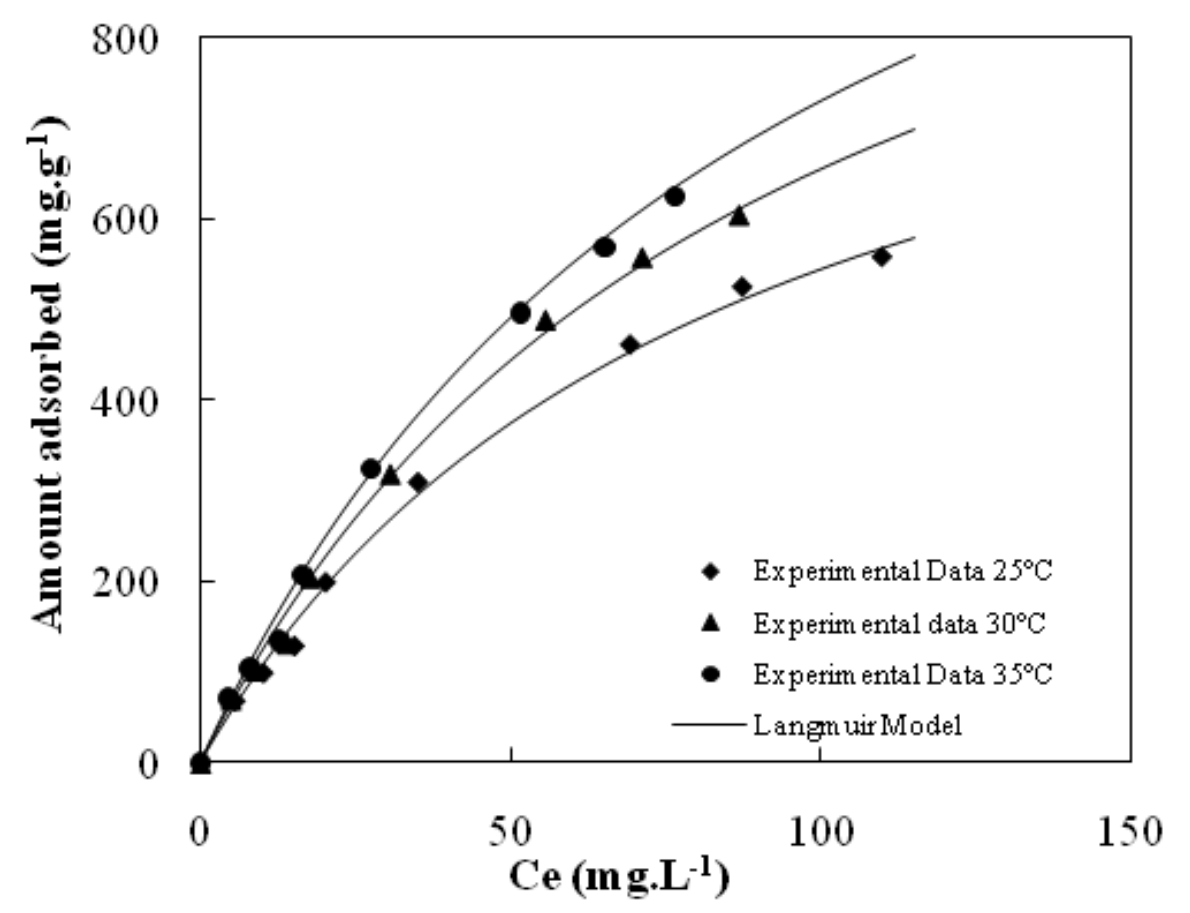

Figure 8. Equilibrium data of COD adsorption onto JSAC and non-linear fits of Langmuir adsorption model.

As shown in Figure 8, the Langmuir model closely describes the COD adsorption equilibrium data on JSAC at all three temperatures with significant coefficient $\mathrm{R}^{2}$ (see Table 4). The correlation coefficient $\mathrm{R}^{2}$ is higher than 0.98 , meaning that Langmuir isotherm can be used satisfactorily to describe the adsorption of COD from wastewater on JSAC. The results show that the amount of COD adsorbed experimentally at equilibrium on JSAC at room temperature is about $1000 \mathrm{mg} \mathrm{O}_{2} \mathrm{~g}^{-1}$. It can also be noted that maximum adsorption capacity $\left(\mathrm{q}_{\mathrm{m}}\right)$ increased with increase in temperature from $1000 \mathrm{mg} \mathrm{O}_{2} \mathrm{~g}^{-1}$ to $1429 \mathrm{mg} \mathrm{O}_{2} \mathrm{~g}^{-1}$, which inferred that the adsorption of COD on JSAC might be endothermic. This is due to the increase in the kinetic energy availability at the active sites of 
the JSAC adsorbent. Also, they are raising the solution temperature results in expansion of the Table 4. Isotherm model parameters for COD adsorption

\begin{tabular}{l|l} 
Parameters & $25^{\circ} \mathrm{C}$ \\
\hline $\mathrm{q}_{\mathrm{m}}\left(\mathrm{mg} \cdot \mathrm{g}^{-1}\right)$ & 1000 \\
\hline $\mathrm{K}_{\mathrm{L}}\left(\mathrm{L} \cdot \mathrm{mg}^{-1}\right)$ & 0.012 \\
$\mathrm{R}^{2}$ & 0.98
\end{tabular}

In this study, the adsorbent used showed a high adsorbent capacity for $\mathrm{COD}$ at $25^{\circ} \mathrm{C}$ compared with the results obtained with other adsorbents of different nature fro COD removal and in the same ones as reported in the literature ${ }^{6,33-40}$.

\section{Conclusions}

Results show that the adsorption of COD onto locally prepared jujube shells activated carbon (JSAC) to be an efficient and promising method for the treatment of wastewater obtained from Fez city. The efficiency of the process is evaluated in terms of COD and color removal. Adsorption process onto JSAC leads to an enhancement on COD and color of $72 \%$ and $83 \%$, respectively. The adsorption of COD onto JSAC was best fitted by the pseudo-secondorder model, and the equilibrium data followed the Langmuir isotherm model, with a monolayer adsorption capacity of $1000 \mathrm{mg} \cdot \mathrm{g}^{-1}$ at $25^{\circ} \mathrm{C}$. Results indicated that the adsorption process using a new low cost activated carbon derived from jujube shells is an efficient and promising method for the treatment of organic molecules from wastewater from Fez city.

\section{References}

1- S. S. Salih, T. K. Ghosh, Highly efficient competitive removal of $\mathrm{Pb}$ (II) and $\mathrm{Ni}$ (II) by chitosan/diatomaceous earth composite. J. of Environ. Chem. Eng., 2018, 6(1), 435-443.

2- S. S. Salih, T. K. Ghosh, Preparation and characterization of bioadsorbent beads for chromium and zinc ions adsorption. Cogent Environ. Sci., 2017, 3(1), 1401577.

3- Z. Chaouki, I. El Mrabet, F. Khalil, M. Ijjaali, S. Rafqah, S. Anouar, M. Nawdali, H. Valdés, H. Zaitan, Use of coagulation-flocculation process for the treatment of the landfill leachates of Casablanca city (Morocco)., J. Mater. Environ. Sci., 2017, 8(8), 2781-2791.

4- A.K. Jain, V.K. Gupta, A. Bhatnagar, Suhas, Utilization of industrial waste products as adsorbents for the removal of dyes, J. Hazard. Mater., 2003, 101, 31-42.

5- Y.S. Ho, G. McKay, Sorption of dyes and copper ions onto biosorbents, Process Biochem., 2003, 38, 1047-1061.

6- D.D. Duong, Adsorption Analysis: Equilibria and Kinetics, Imperial College Press, London, 1998.

7- S. Babel, T.A. Kurniawan, Low-cost adsorbents for heavy metals uptake from contaminated pores within the adsorbent particles, which in turn enhances the adsorption capacity.

onto JSAC.

\begin{tabular}{|l|l|}
\hline $30^{\circ} \mathrm{C}$ & $35^{\circ}$ \\
\hline 1250 & 1429 \\
\hline 0.011 & 0.011 \\
\hline 0.99 & 0.98 \\
\hline
\end{tabular}

water: a review, J. Hazard. Mater., 2003, 97, 219-243.

8- A. Baran, E. Black, S.H. Baysal, S. Onal, Comparative studies on the adsorption of $\mathrm{Cr}$ (VI) ions on to various sorbents, Bioresour. Technol., 2007, 98, 661-665.

9- D. Mohan, K. Singh, V. Singh, Wastewater treatment using low cost activated carbons derived from agricultural by-products: a case study, J. Hazard. Mater., 2008, 52, 1045-1053.

10-E. El-Sharkawy, A. Soliman, K. Al-Amer, Comparative study for the removal of methylene blue via adsorption and photocatalytic degradation, J. Colloid Interface Sci., 2007, 310, 498-508.

11-M. Maraghni, M. Gorai, and M. Neffati, Seed germination at different temperatures and water stress levels, and seedling emergence from different depths of Ziziphus lotus. South African Journal of Botany, 2010, 76(3), 453-459.

12- C. Moreno-Castilla, F. Carrasco-Marín, M.V. López-Ramón, M.A. Álvarez-Merino, Chemical and physical activation of olive-mill waste water to produce activated carbons. Carbon, 2001, 39, 1415-1420.

13-H.P. Boehm, Some aspects of the surface chemistry of carbon blacks and other carbons, Carbon 1994, 32, 759-764.

14-W. Stumm, Chemistry of the Solid-Water Interface. J. Wiley \& Sons, Inc., New York., 1992

15-Standard methods for the examination of water and wastewater. Washington, DC: American Public Health Association (APHA), 2012.

16- C. Tizaoui, L. Bouselmi, L. Mansouri, A. Ghrabi, Landfill leachate treatment with ozone and ozone/hydrogen peroxide systems, J. Hazard. Mat., 2006,140, 316-324.

17-E. Güneş, E. Demir, Y. Güneş, A. Hanedar, Characterization and treatment alternatives of industrial container and drum cleaning wastewater: Comparison of Fenton-like process and combined coagulation/oxidation processes." Separation and Purification Techno., 2019, 209, 426-433.

18- Z. Chaouki, F. Khalil., M. Ijjaali, H. Valdés, S. Rafqah, M. Sarakha, H. Zaitan, Use of a combination of coagulation and adsorption process for the landfill leachate treatment from Casablanca city, Desal. and Water. Treat., 2017, 83, 262-271.

19- M.I. Al-Wabel, W.S. Al Yehya, A.S. AL-Farraj, S.E. El-Maghraby, Characteristics of landfill 
leachates and bio-solids of municipal solid waste (MSW) in Riyadh City. Saudi Arabia, J. Saudi Soc. Agric. Sci., 2011, 10, 65-70.

20- W. Yang, J. Wang, M. Hua, Y. Zhang, X. Shi, Characterization of effluent organic matter from different coking wastewater treatment plants, Chemosphere, 2018, 203, 68-75.

21-V.G. Teixeira, F.M.B. Coutinho, A.S. Gomes, The most important methods for the characterization of porosity of styrenedivinylbenzene based resins, Quim. Nova, 2001, 24, 808-818.

22- K.S.W. Sing, D.H. Everett, R.A.W. Haul, L. Moscou, R.A. Pierotti, J. Rouquerol, T. Siemieniewska, Reporting physisorption data for gas/solid systems with special reference to the determination of surface area and porosity, Pure Appl. Chem., 1985, 57, 603-619.

23-B.K. Pradhan, N.K. Sandle, Effect of different oxidizing agent treatments on the surface properties of activated carbons, Carbon, 1999, 37, 1323-1332.

24-D. Prahas, Y. Kartika, N. Indraswati, S. Ismadji, Activated carbon from jackfruit peel waste by $\mathrm{H}_{3} \mathrm{PO}_{4}$ chemical activation: pore structure and surface chemistry characterization, Chem. Eng. J., 2008, 140, 32-42.

25- K. Moodley, R. Singh, E.T. Musapatika, M.S. Onyango, A. Ochieng, Removal of nickel from wastewater using an agricultural adsorbent, Water SA, 2011, 37, 41-46.

26- R. Cossu, R.R. Rossetti, The PAF model: an integrated approach for landfill sustainability, Waste Manage., 2003, 23, 37-44.

27-C.P. Das, L.N. Patnaik, Use of industrial waste for reduction of COD from paper mill effluent, Indian Journal of Environ. Health, 2001, 43 (1), 21-27.

28- A. Shehzad, M.J.K. Bashir, S. Sethupathi, M. Younas, J.W. Lim, Decolorization of heavily polluted landfill leachate treatment through microwave heating using activated biochar as an adsorbent, Int. J. Plant, Animal Environ Sci., 2016, 6, 255-267.

29- J. Fujiki, T. Shinomiya, T. Kawakita, S. Ishibashi, E. Furuya, Experimental determination of fluid-film mass transfer coefficient from adsorption uptake curve, Chem. Eng. J., 2011, 173, 49-54.
30- S. Lagergren, About the theory of so-called adsorption of soluble substances, K. Sven vetensk.akad. Handl., $\mathbf{1 8 9 8}, 24,1-39$.

31- Y.S. Ho, G. McKay, D.A.J. Wase, C.F. Forster, Study of the sorption of divalent metal ions on to peat, Adsorp. Sci. Technol., 2000, 18(7) 639-650.

32- I. Langmuir, Adsorption of gases on plain surfaces of glass mica platinum, J. Am. Chem. Soc., 1918, 40(9), 1361-1403.

33-K.R. Hall, L.C. Eagleton, A. Acrivos, T. Vermeulen, Pore-solid-diffusion kinetics in fixed-bed adsorption under constant-pattern conditions, Ind. Eng. Chem. Res., 1966, 5(2), 212-216.

34- K.Y. Foo, L.K. Lee, B.H. Hameed, Batch adsorption of semi-aerobic landfill leachate by granular activated carbon prepared by microwave heating, Chem. Eng. J., 2013, 222, 259-264.

35- Y. Pan, Y. Zhu, Z. Xu, R. Lu, Z. Zhang, M. Liang, H. Liu, Adsorption removal of COD from wastewater by the activated carbons prepared from sugarcane bagasse, in 5th International Conference on Bioinformatics and Biomedical Engineering, ICBBE 2011, Art. No. 5781097, 2011.

36- A.A. Halim, H.A. Aziz, M.A.M. Johari, K.S. Ariffin, Comparison study of ammonia and COD adsorption on zeolite, activated carbon and composite materials in landfill leachate treatment, Desalination, 2010, 262, 31-35.

37-M.A.O. Badmus, T.O.K. Audu, Periwinkle shell: based granular activated carbon for treatment of chemical oxygen demand (COD) in industrial wastewater, Can. J. Chem. Eng., 2009, 87, 69-77.

38-A.A. Ahmad, B.H. Hameed, Reduction of COD and colour of dyeing effluent from a cotton textile mill by adsorption onto bamboo-based activated carbon, J. Hazard. Mater., 2009, 172, 1538-1543.

39-M.M. Lakdawala, Y.S. Patel, The effect of lowcost material bagasse fly ash to the removal of COD contributing component of combined wastewater of sugar industry, Arch. Adv. Appl. Sci. Res., 2012, 4, 852-857.

40-Y.N. Lim, G. Shaaban, C.Y. Yin, Treatment of landfill leachate using palm shell activated carbon column: axial dispersion modelling and treatment profile, Chem. Eng. J., 2009, 146, 86-89. 